En Bretagne, l'infection du porc par le virus d'Aujeszky est largement répandue $(7,4$ p. roo) des sérums contiennent des anticorps anti Aujeszky).

Les premiers résultats de l'extension de l'enquête au reste de la France révèlent la présence du virus dans plusieurs départements où son existence n'ava.it jamais été soupçonnée.

\title{
SUMMARY
}

EPIDEMIOLOGICAL STUDIES OF AUJESZKY'S DISEASE IN BRITTANY

An epidemiological study of Aujeszky's disease in pigs is in progress in Britanny. It concerns searching for the seats of this disease, isolation of the virus $(23$ strains isolated between 1968 and October 1972) and determination of the unapparent infection by detection of neutralizing antibodies in the blood sera of boars and sows taken at random in slaughter houses. In Brittany the infection of pigs by the Aujeszky virus is widespread $(7,4 \mathrm{p}$. IOO of the sera contain anti Aujeszky antibodies).

The first results of the extension of the study to the rest of France reveal the presence of this disease in several departments.

\section{POUVOIR IMMUNIGÈne ET DIFFUSIBILITÉ D'UN MUTANT FROID DE LA PESTE PORCINE CLASSIQUE UTILISÉ SUR LE TERRAIN}

\author{
J.-M. AYNAUD et C. TEXIER* \\ Station de Recherches de Virologie et d'Immunologie, I. N.R. A., \\ 78850 Thiverval Grignon \\ * Institut technique du Porc, \\ 149 rue de Bercy \\ 75579 Paris Cedex 12
}

\section{RÉSUMÉ}

Sur le terrain dans les conditions de la pratique, on a vacciné I 30 porcelets de $32 \mathrm{~kg}$ au milieu desquels ont été placés en cohabitation $3^{\circ}$ animaux " témoins de contact " non vaccinés en vue d'étudier la diffusion éventuelle du virus.

Vers $102 \mathrm{~kg}$ environ, on a évalué l'immunité anti peste porcine à l'aide de la recherche des anticorps neutralisants spécifiques présents dans le sérum par la mise en ouvre de la séroneutralisation en culture cellulaire et également à l'aide de la recherche de la résistance à l'épreuve virulente.

Les résultats obtenus révèlent que Ioo $\mathrm{p}$. Ioo des animaux vaccinés et $19 \mathrm{p}$. Ioo des animaux "témoins de contact " sont immunisés contre la peste porcine. L'intensité et la durée de l'immunité ainsi obtenue ainsi que la diffusion limitée du virus immunisant font l'objet de la discussion. 


\title{
SUMMARY
}

\section{IMMUNIGEN EFFECT AND DIFFUSIBIIITY}

\section{OF A COLD MUTANT OF SWINE FEVER IN FIELD EXPERIMENT}

On the field and in the conditions of pratice, r 30 piglets of $32 \mathrm{~kg}$ were vaccinated. 30 non vaccinated animals, "contact controls" were placed among the experimental ones in order to study the possible diffusion of the virus.

At a weight of about $\mathrm{I} 20 \mathrm{~kg}$, we estimated the anti swine fever specific neutralizing antibodies in the blood serum. This was done by seroneutralization in cell culture and also by determination of resistance to the virulent test.

The results obtained revealed that Ioo p. Ioo of the vaccinated animals and I $9 \mathrm{p}$. roo of the " contact controls" were immunized against swine fever. The intensity and duration of the thus obtained immunity as well as the limited diffusion of the immunizing virus are discussed.

\section{EXAMENS HADIOGRAPHIQUES ET NÉCROPSIQUES DE NEZ DE PORC}

\author{
PREMIERS RÉSULTATS \\ P. DANDO, J. GRUAND et L. OLLIVIER \\ Station de Génétique quantitative et appliquée, \\ Centre national de Recherches zootechniques, I. N.R. A., \\ 78350 Jouy en Josas
}

\section{RÉSUMÉ}

Un échantillon de 95 mâles entiers et un échantillon comprenant 75 femelles et 74 mâles castrés ont été soumis à un examen radiographique du nez vers le poids de $4^{\circ} \mathrm{kg}$ et abattus vers $100 \mathrm{~kg}$. Les nez ont alors été coupés transversalement à l'arrière des canines. Les radiographies ont été examinées et classées indépendamment par deux observateurs, entre lesquels la corrélation est de 0,7 . Les coupes ont été examinées une seule fois et la corrélation entre la note radiographique et la note de coupe est de o,3I. La faible concordance entre les deux techniques semble pouvoir s'expliquer par le fait que de nombreux cas d'atrophie des cornets nasaux apparents sur l'image radiographique échappent à l'examen de la coupe en abattoir. L'analyse des deux échantillons confirme l'influence de l'hérédité sur le degré des altérations nasales et révèle une atrophie des cornets nasaux significativement plus marquée chez les mâles castrés que chez les femelles. 